\title{
Counselling by primary care physicians may help patients with heartburn-predominant uninvestigated dyspepsia
}

\author{
Pierre Paré MD FRCPC FACG ${ }^{1}$, Joanna Lee M Math², lan A Hawes BSP ACPR CCPE ${ }^{2}$
}

\begin{abstract}
P Paré, J Lee, IA Hawes. Counselling by primary care physicians may help patients with heartburn-predominant uninvestigated dyspepsia. Can J Gastroenterol 2010;24(3):189-195.
\end{abstract}

OBJECTIVE: To determine whether strategies to counsel and empower patients with heartburn-predominant dyspepsia could improve healthrelated quality of life.

METHODS: Using a cluster randomized, parallel group, multicentre design, nine centres were assigned to provide either basic or comprehensive counselling to patients (age range 18 to 50 years) presenting with heartburn-predominant upper gastrointestinal symptoms, who would be considered for drug therapy without further investigation. Patients were treated for four weeks with esomeprazole $40 \mathrm{mg}$ once daily, followed by six months of treatment that was at the physician's discretion. The primary end point was the baseline change in Quality of Life in Reflux and Dyspepsia (QOLRAD) questionnaire score.

RESULTS: A total of 135 patients from nine centres were included in the intention-to-treat analysis. There was a statistically significant baseline improvement in all domains of the QOLRAD questionnaire in both study arms at four and seven months $(P<0.0001)$. After four months, the overall mean change in QOLRAD score appeared greater in the comprehensive counselling group than in the basic counselling group (1.77 versus 1.47 , respectively); however, this difference was not statistically significant $(\mathrm{P}=0.07)$. After seven months, the overall mean baseline change in QOLRAD score between the comprehensive and basic counselling groups was not statistically significant (1.69 versus 1.56 , respectively; $\mathrm{P}=0.63$ ).

CONCLUSIONS: A standardized, comprehensive counselling intervention showed a positive initial trend in improving quality of life in patients with heartburn-predominant uninvestigated dyspepsia. Further investigation is needed to confirm the potential benefits of providing patients with comprehensive counselling regarding disease management.

Key Words: Counselling; Heartburn-predominant; Quality of life; Uninvestigated dyspepsia

\author{
Les conseils des médecins de première ligne \\ peuvent aider les patients ayant une dyspepsie \\ inexplorée se manifestant surtout par des brûlures \\ d'estomac
}

OBJECTIF : Déterminer si les stratégies pour conseiller et habiliter les patients ayant une dyspepsie se manifestant surtout par des brûlures d'estomac pourraient améliorer la qualité de vie liée à la santé.

MÉTHODOLOGIE : Au moyen d'une méthodologie multicentrique groupée aléatoire avec contrôle parallèle, neuf centres ont été désignés pour donner des conseils de base ou des conseils détaillés aux patients (plage de 18 à 50 ans) ayant des symptômes œesogastroduodénaux se manifestant surtout par des brûlures d'estomac et pour qui on envisagerait une pharmacothérapie sans exploration supplémentaire. Les patients ont été traités à l'aide d'une dose quotidienne de $40 \mathrm{mg}$ d'ésoméprazole pendant quatre semaines, suivie d'un traitement de six mois au gré du médecin. Le paramètre ultime primaire était l'indice du questionnaire QOLRAD sur le changement de qualité de vie à l'égard du reflux et de la dyspepsie par rapport aux valeurs de départ.

RÉSULTATS : Au total, 135 patients des neuf centres ont participé à l'analyse du projet thérapeutique. On a constaté une amélioration statistiquement significative par rapport à la valeur de départ dans tous les domaines du questionnaire QOLRAD au bout de quatre et sept mois, dans les deux volets de l'étude $(P<0,0001)$. Au bout de quatre mois, le changement global moyen de l'indice QOLRAD semblait plus important dans le groupe ayant reçu des conseils détaillés que dans celui ayant reçu des conseils de base ( 1,77 par rapport à 1,47 , respectivement), mais cette différence n'était pas statistiquement significative $(P=0,07)$. Au bout de sept mois, le changement global moyen de l'indice QOLRAD par rapport à la valeur de départ entre les groupes ayant reçu des conseils détaillés ou des conseils de base n'était pas statistiquement significatif (1,69 par rapport à 1,56 , respectivement; $\mathrm{P}=0,63)$.

CONCLUSIONS : Une intervention normalisée de conseils détaillés s'associait à une tendance initiale positive vers l'amélioration de la qualité de vie des patients ayant une dyspepsie inexplorée se manifestant surtout par des brûlures d'estomac. Il faudra approfondir les recherches pour confirmer les bienfaits potentiels de conseils détaillés sur la prise en charge de la maladie. 
TABLE 1

Template for intervention strategy

1. Educate on the natural history of symptoms/disease
Common symptoms
Heartburn and acid regurgitation
Abnormal function of gastroesophageal sphincter: a valve-like mechanism to
prevent reflux of acid and/or food in esophagus
Dyspeptic symptoms: abnormal stomach function
Slow emptying of stomach
Increased sensitivity of stomach to distension
Lifestyle modifications
Not the cause of these symptoms but modulate their severity or perception
Eating
Avoid high-fat meals, large meals, eating before retiring/lying down
No specific diet otherwise
Potential irritants
Juices, chocolate, mint, alcohol
Smoking cessation
Weight control
Methods to control acid reflux
Acid-neutralizing drug (antacids)
Inhibiting acid secretion

2. Address the patient's expectations for symptom relief

Heartburn and acid regurgitations

Highly responsive to acid-suppressive therapy

Other dyspeptic symptoms

Variably and less responsive to acid-suppressive therapy

3. Address reason(s) for consulting

"You have had these symptoms for sometime, what prompted you to seek consultation at this point in time?"

Items for discussion

Severity and frequency of symptoms

Personal concern about a serious disease

Emotional/psychological distress

Anxiety

Depression

Difficulty arising from major life events and psychosocial issues

Reassure after eliciting the patient's worries and concerns

Note: The discussion should, as much as possible, be of the same content and be delivered in the same manner to all subjects

Only a minority of individuals with GERD seek advice from a health care professional and, for many subjects, dyspepsia persists for several months or years. Compared with asymptomatic individuals, those seeking health care have impaired HRQoL, increased work absenteeism and decreased productivity (12). The reasons for seeking medical help are only partially explained by the severity or frequency of symptoms (13). In a patient-based study of patients with heartburn and/or functional dyspepsia (14), 65\% reported anxiety and worry about their condition, followed by various psychological problems (35\%) and dyspepsia itself (26\%). Patient fear and anxiety related to the possible presence of a more serious condition in the presence of GERD and/or dyspepsia has also been supported by community- $(15,16)$ and population-based studies $(17,18)$. When diagnostic and prognostic information is provided to primary care patients presenting with physical symptoms, there is short-term improvement in symptoms and functional status (19). A general therapeutic approach without pharmacotherapy (20) and overtly discussing the motives for consultation (21) have been shown to reduce symptoms and health care visits in patients with irritable bowel syndrome. Therefore, factors other than initial and long-term drug therapy are likely to influence the patient's behaviour in managing their disease; indeed, patient concerns and fear of serious disease, anxiety and psychological issues account for an important part of the differences in health care use. Other factors may relate to patients' expectations and education on the chronic nature of their symptoms. Strategies to counsel and empower the patient could influence global management and outcomes, leading to improved HRQoL and satisfaction, and decreased health care system costs.

In the present study, we assessed the benefit of a six-month patient-empowering and counselling strategy after four weeks of initial therapy with esomeprazole $40 \mathrm{mg}$ once daily in primary care patients with heartburn-predominant uninvestigated dyspepsia. The primary objective was to evaluate the four-and seven-month change from baseline in dimensions of HRQoL using the Quality of Life Questionnaire in Reflux and Dyspepsia (QOLRAD) (22) for patients who received comprehensive counselling versus those who received basic counselling.

\section{METHODS}

The present study was performed according to a parallel group, multicentre, cluster randomized design. Before subjects were enrolled, the participating centres (urban family practice clinics) were randomly assigned to provide only one type of counselling intervention: basic or comprehensive counselling. This was to minimize potential bias that may have been introduced by the same investigator providing the two counselling interventions.

Patients were initially treated with four weeks of oral esomeprazole therapy ( $40 \mathrm{mg}$ once daily). Treatment in the following six months was open to the physician's discretion. The duration of treatment was in accordance with the results of the CADET (23) group of studies and the Canadian Dyspepsia Working Group guidelines (6).

\section{Study plan}

The study enrolled men and women 18 to 50 years of age, with a history of heartburn-predominant symptoms (continuous or intermittent) lasting a minimum of one month. Study subjects were also required to identify heartburn as their most bothersome symptom on the specific symptom subtype scale at visit 1 , and have overall symptoms of moderate severity (Global Overall Symptom [GOS] score of 4 or higher at visit 1). Patients were excluded if they were currently experiencing or had a history of gastric or duodenal ulcers, gastrointestinal malignancy, erosive esophagitis, Zollinger-Ellison syndrome or primary esophageal motility disorders, documented upper gastrointestinal surgery, Helicobacter pylori eradication or attempted eradication therapy in the previous six months, pregnancy or lactation, chronic alcoholism or drug abuse. Treatment with PPIs, $\mathrm{H}_{2}$-receptor antagonists or prokinetics during the 30 days before visit 1 was also not permitted.

The counselling interventions were delivered in a standardized manner using the template provided in Table 1. Training was provided by the same individual (PP) to all participating physicians, and separately to those randomly assigned to basic 
counselling and those to comprehensive counselling. Groups did not have access to the template of the other group. One group of centres was randomly assigned to basic counselling, which included only one component. The other group of centres was randomly assigned to comprehensive counselling, which included three components. Basic counselling (component 1 only) aimed to provide education on the natural course of the disease and symptoms, including lifestyle changes that could help reduce the frequency and severity of symptoms as well as methods to help relieve the symptoms when present. Comprehensive counselling included the components of basic counselling and two other components to address the subject's expectations concerning symptom relief (component 2) and to address the reasons why subjects consult their physicians for these symptoms (component 3). Component 2 aimed to elaborate on the symptoms of the disease and the nature of the symptoms that would respond best to acid-suppressive therapy. Component 3 focused on the reasons why the subjects believed they needed to consult their physician concerning their symptoms and allaying any fears or concerns.

Investigators provided the counselling intervention their centre was randomly assigned to by using a template to standardize the protocol at the first visit before esomeprazole therapy and one month later, at the end of initial esomeprazole therapy. Although the investigators were required to answer any questions that were asked by patients, questions were not solicited.

The study plan included visits at entry and at one, four and seven months (Figure 1). At each visit, the QOLRAD (22), GOS (24,25) and Reflux Disease Questionnaire (RDQ [26]) questionnaires were completed. Patients were provided with journals at each study visit, with instructions to record information regarding health care visits, costs incurred and days of work or salary lost, both dyspepsia-related and those incurred for any other concomitant illnesses. Patients were contacted by telephone at weeks 10 and 22, to enquire about adverse events and any new concomitant medications, including any medicines used to treat their dyspepsia and to remind them to record all health care costs incurred in the journal.

At the end of the study (month 7), all subjects were assessed for their overall satisfaction with the counselling they had received. Patients who received comprehensive counselling were also questioned to assess which component of the intervention they found most helpful. The investigator's satisfaction with the management strategies was also assessed.

\section{Statistical analysis}

Statistical analyses were performed, using SAS version 8.2 (SAS Institute, USA).

For hypothesis testing, a $\mathrm{P}<0.05$ probability of type I error was considered to be statistically significant. Changes in baseline QOLRAD scores and GOS scale after one, four and seven months were analyzed using analysis of covariance with factors of the study arms and language, if applicable. The difference in relative baseline response to the QOLRAD questions at four and seven months was summarized for the five separate domains to describe the primary efficacy end point. In addition, the change from baseline in overall quality of life score, derived as average of all QOLRAD questions, was calculated and reported. In view of the exploratory nature of the study, no adjustment for multiplicity was performed. The baseline score

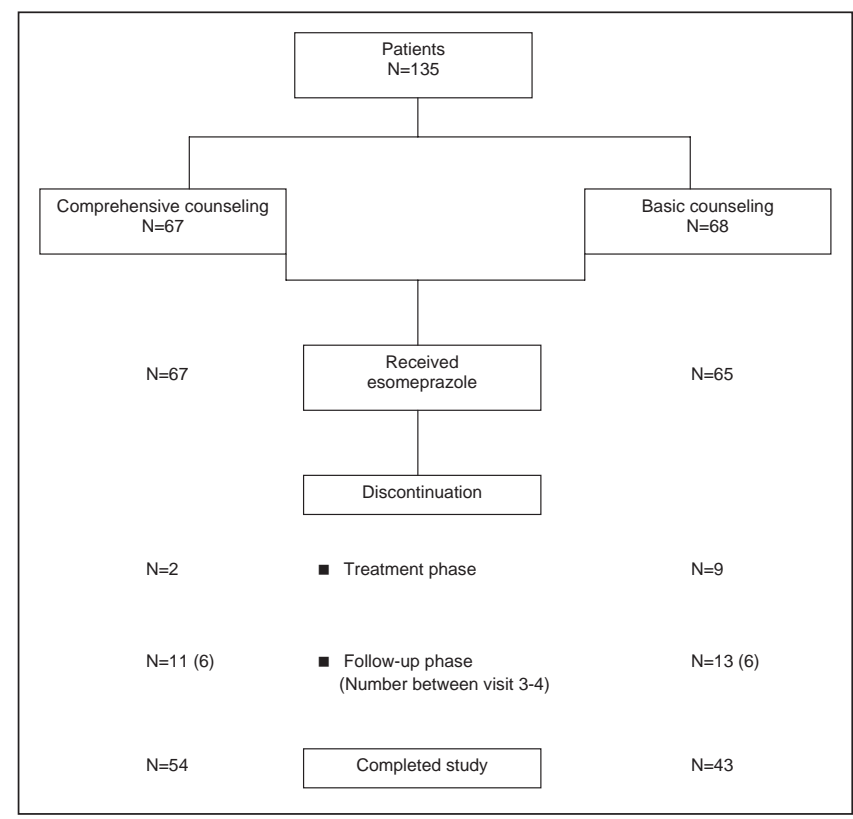

Figure 1) Subject disposition

was included in the model as a covariate and the centre effect was treated as a random effect. Sixty per cent of nonmissing QOLRAD data was the minimum requirement for the mean calculation within a domain. The frequency and percentages of subjects with symptom relief, resolution and improvement were summarized for the two study arms after one, four and seven months, and 95\% CIs for the estimated percentages were determined. The change in baseline RDQ scores after one, four and seven months was analyzed using the signed rank test. All missing values were determined using the last observation carried forward method. Least-square means, 95\% CIs and graphical presentations are included in the presentation of data. The confidence limits for the health economics variable were computed using the nonparametric bootstrap method.

The primary approach to statistical analyses for all efficacy and patient-reported outcomes was an intention-to-treat (ITT) analysis. All randomly assigned patients were included in the ITT population. All subjects who received at least one dose of study medication were included in the analysis of safety data.

The present study was exploratory; therefore, appropriate sample size with adequate power was not determined. Three investigative sites were to enrol 65 subjects who would be provided with comprehensive counselling, while six other investigative sites were to enrol 65 subjects who would be provided with basic counselling. Of 130 subjects enrolled, 100 subjects (50 in each study arm), were expected to complete the full seven-month study period.

\section{RESULTS}

In total, 135 subjects were enrolled and received treatment in nine centres (six basic counselling and three comprehensive counselling). There were one to six primary care physicians at each centre, and each centre enrolled one to 27 patients. All 135 patients were included in the ITT analysis (three patients in the basic counselling group discontinued participation before receiving esomeprazole). Figure 1 illustrates subject participation throughout the study. In the comprehensive counselling 
TABLE 2

Baseline demographics and characteristics

\begin{tabular}{|c|c|c|}
\hline \multirow[b]{2}{*}{ Characteristics } & \multicolumn{2}{|c|}{ Counselling intervention group } \\
\hline & $\begin{array}{c}\text { Comprehensive } \\
\quad(n=67)\end{array}$ & $\begin{array}{l}\text { Basic } \\
(n=68)\end{array}$ \\
\hline \multicolumn{3}{|l|}{ Demographic } \\
\hline \multicolumn{3}{|l|}{ Sex } \\
\hline Men & 54 & 60 \\
\hline Women & 46 & 40 \\
\hline Mean age, years & 39 & 36 \\
\hline \multicolumn{3}{|l|}{ Language } \\
\hline English & 48 & 47 \\
\hline French & 52 & 53 \\
\hline Body mass index, $\mathrm{kg} / \mathrm{m}^{2}$ (mean) & 29.1 & 28.2 \\
\hline \multicolumn{3}{|l|}{ Education } \\
\hline High school or less & 49 & 62 \\
\hline College or above & 51 & 38 \\
\hline \multicolumn{3}{|l|}{ Clinical } \\
\hline Heartburn & 100 & 100 \\
\hline Mean duration of heartburn, years & 5.5 & 5.8 \\
\hline $\begin{array}{l}\text { Previous procedures for } \\
\text { gastrointestinal symptoms }\end{array}$ & 30 & 26 \\
\hline $\begin{array}{l}\text { QOLRAD overall score, } \\
\text { mean }(95 \% \mathrm{Cl})\end{array}$ & $4.36(4.08-4.64)$ & $4.06(3.80-4.32)$ \\
\hline \multicolumn{3}{|l|}{ Global overall symptoms } \\
\hline Moderate $($ score $=4)$ & 52 & 25 \\
\hline Moderately severe $($ score $=5$ ) & 36 & 41 \\
\hline Severe/very severe $($ score $=6$ or 7 ) & 12 & 34 \\
\hline Mean score $(95 \% \mathrm{Cl})$ & $4.6(4.4-4.8)$ & $5.1(4.9-5.4)$ \\
\hline Overall RDQ score, mean $(95 \% \mathrm{Cl})$ & $30.1(27-33.1)$ & $33.2(30.8-35.7)$ \\
\hline
\end{tabular}

Data are presented as \%, unless indicated otherwise. QOLRAD Quality of Life in Reflux and Dyspepsia; RDQ Reflux Disease Questionnaire

group, 13 patients were lost to follow-up. In the basic counselling group, 15 patients were lost to follow-up, four patients withdrew their consent and three patients did not fulfill eligibility criteria. The baseline demographic characteristics of the two intervention groups were similar (Table 2). Regarding clinical characteristics, the basic counselling group showed a lower QOLRAD mean score, a higher GOS and overall RDQ mean score than the same scores in the comprehensive counselling group. The corresponding baseline value was included in the analysis for adjustment. Regarding specific symptom subtypes, epigastric pain (34\% versus 50\%), epigastric discomfort (27\% versus $51 \%$ ) and regurgitation ( $37 \%$ versus $48 \%$ ) were reported more often in the basic than in the comprehensive counselling group, respectively. Overall, patients reported bloating (31\%), belching $(37 \%)$, nausea $(17 \%)$, early satiety $(21 \%)$ and postprandial fullness $(32 \%)$. The most bothersome symptom was heartburn in all patients of each group.

\section{Primary outcome: HRQoL}

Treatment phase: Figure 2 depicts the mean scores for the QOLRAD questionnaire during the course of the study. Both groups showed a statistically significant improvement from baseline at one month $(\mathrm{P}<0.001)$. The overall mean change in QOLRAD score from baseline to one month was 1.85 for the comprehensive counselling group and 2.00 for the basic counselling group ( $\mathrm{P}=0.62$ between groups). There were no

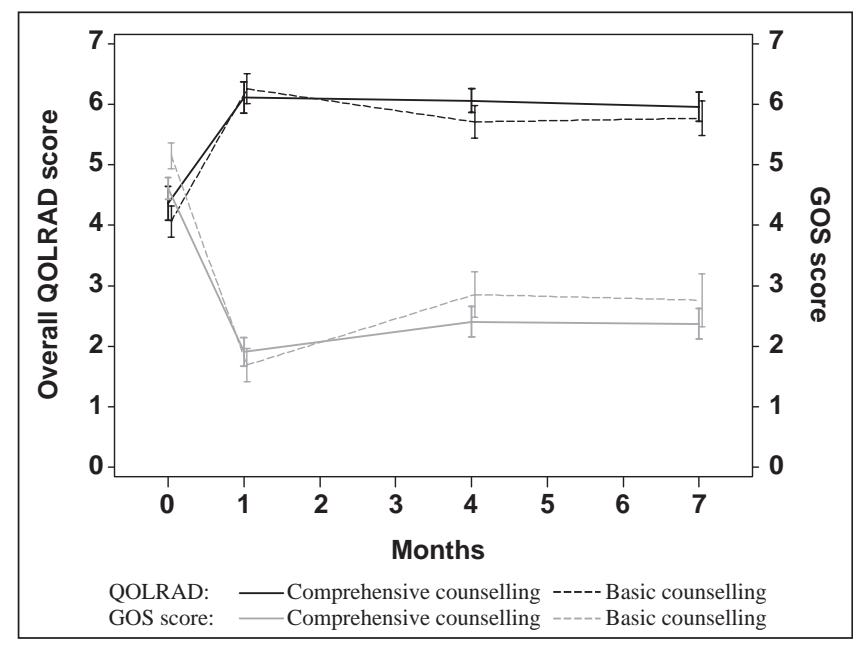

Figure 2) Overall Quality of Life in Reflux and Dyspepsia (QOLRAD) and Global Overall Symptom (GOS) scores over time (mean and 95\% CIs)

statistically significant differences in any domain when comparing between groups.

Follow-up phase: A statistically significant baseline improvement in all domains of the QOLRAD questionnaire at four and seven months was observed in both study arms $(\mathrm{P}<0.001)$. The overall mean baseline change in QOLRAD score at four months was 1.77 for the comprehensive counselling group and 1.47 for the basic counselling group $(\mathrm{P}=0.07)$. The former group showed a statistically significant improvement in QOLRAD score from baseline to four months in the emotional distress domain compared with the basic counselling group (1.96 and 1.54, respectively; $\mathrm{P}=0.03$ ). The overall mean change in QOLRAD score from baseline to seven months was 1.69 for the comprehensive counselling group and 1.57 for the basic counselling group $(P=0.63)$. There were no statistically significant differences in any domains between groups from baseline to seven months.

Compared with the end of treatment phase (month 1), when both sessions of counselling had been delivered, the overall QOLRAD score three months later declined significantly more in the basic counselling group than in the comprehensive counselling group (mean change 0.51 and 0.10 , respectively; $\mathrm{P}=0.005$ ). All domains of the $\mathrm{QOLRAD}$ questionnaire, except sleep disturbance, showed statistically significant differences between the two groups. At six months after the end of treatment phase, the changes in the overall QOLRAD score or any of its domains, did not differ between the two study arms.

\section{Secondary outcomes: Symptom assessment}

Both groups showed a statistically significant improvement in GOS score from baseline to one, four and seven months $(\mathrm{P}=0.0001)$. The changes in GOS score at four and seven months did not differ significantly between the two groups.

After the end of the initial four weeks of treatment with esomeprazole, both groups showed a progressive decrease in the proportion of patients with symptom improvement, relief and resolution during the follow-up phase (symptom relief [GOS 2 or less] at one, four and seven months: comprehensive counselling: $78 \%, 60 \%$ and $66 \%$; basic counselling: $83 \%, 48 \%$ and 
$58 \%$, respectively). There was no significant difference at four months between the two groups in terms of symptom improvement, relief or resolution. At four and seven months, there was a trend showing that GOS worsened more in the basic than in the comprehensive counselling group, but there was no statistically significant difference between groups $(0.6$ versus 0.9 at four months $[\mathrm{P}=0.47]$ and 0.6 versus 0.7 at seven months $[\mathrm{P}=0.77]$, respectively).

A similar number of subjects had symptom relief measured by the specific symptom subtype scale (a change from a score of 4 or greater at baseline to a score of 2 or less at seven months) in the comprehensive and basic counselling groups (72\% to $85 \%$ versus $64 \%$ to $92 \%$ ). When individual scores of the RDQ were compared with baseline at one, four and seven months, both groups showed a statistically significant improvement $(\mathrm{P}<0.001)$. Generally, the comprehensive counselling group had more improvement in their RDQ scores than with basic counselling; however, frequency of regurgitation, between seven months and baseline, was the only domain that showed statistical significance between the two groups $(\mathrm{P}=0.034)$.

\section{Subject and physician satisfaction after seven months}

More subjects in the comprehensive counselling group (53.7\%) were completely satisfied with therapy than in the basic counselling group (38.6\%), but the difference was not statistically significant. Overall, $100 \%$ of the comprehensive counselling group were at least 'satisfied' with the counselling they received, compared with $93.2 \%$ of those who received basic counselling.

Based on a 4-point scale, most subjects who received the comprehensive counselling intervention reported the three components of the counselling intervention (education [92.3\%], expectations [96.1\%] and reasons for consulting their physician [94.2\%]) as being 'at least helpful'.

Overall, more patients were satisfied with the counselling intervention than the physicians for both the comprehensive (57.4\%) and basic counselling groups (52.3\%).

All investigators in the comprehensive and basic counselling groups reported being 'at least satisfied' with the counselling intervention they provided; $41 \%$ and $30 \%$ of physicians, respectively, quoted being 'very' or 'completely satisfied'.

\section{Health care resource use}

After calculating the health care costs incurred during the study for each subject group and normalizing to yearly costs, there were no statistically significant differences between the comprehensive and basic counselling groups ( $\$ 290.82$ versus $\$ 355.39$; $95 \%$ $\mathrm{CI}$ of difference between groups $-\$ 172.06$ to $\$ 26.33$ ). The major drivers of costs were study medication and the cost of prescription drugs. After the initial one month of esomeprazole therapy and during the six-month usual care phase, PPIs were taken by 27 patients (of a total of 65) and by 24 patients (of a total of 56) during the first three months, and by 12 patients (of a total of 60 ) and seven patients (of a total of 49) during the last three months in the comprehensive and basic counselling groups, respectively. For those who took a PPI as a concomitant medication, the mean duration of PPI treatment during the usual care phase was 95 days (median 98 days, range one to 173 days) in the comprehensive counselling group and 112 days (median 106 days, range 10 to 177 days) in the basic counselling group.

There were no safety or tolerability concerns arising from the study.

\section{DISCUSSION}

The aim of the present study was to evaluate the impact of a disease management counselling intervention on HRQoL in a representative population of patients presenting with heartburn-predominant uninvestigated dyspepsia. A cluster randomization design was used in which sites were assigned to provide either a basic or comprehensive counselling intervention. The basic counselling intervention was developed by the initiating investigator (PP) after consulting primary care physicians. This consultation found that these physicians provided all items of the basic counselling intervention; however, usually over several patient visits rather than in total at one or two visits. In the comprehensive counselling intervention, items not routinely reviewed with patients by primary care physicians were added and were believed to be of clinical relevance by physicians participating in the study.

The present study was exploratory in nature and, therefore, had some inherent limitations. A sample size was not formally calculated and the study design was not optimal. The most natural way to analyze a cluster randomized trial would be to examine the cluster level; for example, one response per centre weighted by centre size. However, because the number of centres in the present study was small, this type of analysis was not a viable option. Due to the small number of centres and patients, some of the variables may not have been sufficiently powered to show a statistically significant difference between the two study groups. Additionally, because the study compared two counselling interventions, the design lacked a true control group in which no counselling was provided.

There was a statistically significant baseline improvement in all domains of the QOLRAD score at four and seven months in both counselling study arms. At four months, the overall mean change in QOLRAD was greater with comprehensive versus basic counselling. Compared with baseline, however, this difference was not statistically significant $(\mathrm{P}=0.07)$, except in the emotional distress domain $(\mathrm{P}=0.03)$. The QOLRAD change at four months compared with the time when the intervention was completed (after the fourweek treatment phase) was statistically greater with comprehensive versus basic counselling; however, the magnitude of the difference may not be clinically relevant. The study results suggest that the patient perception of overall benefits obtained from the two counselling interventions may be similar. This is consistent with the lack of difference in QOLRAD scores at seven months.

Both interventional counselling templates included a discussion on education in the natural history of heartburn-predominant dyspepsia, mechanisms of symptoms, lifestyle modifications and available drug therapies. However, the comprehensive intervention template also addressed two additional topics: patient expectations in symptom relief (discussing the types of symptoms that would be highly responsive to acidsuppressive therapy versus other symptoms that would be variably or less responsive), and patient reasons for consulting with their physician (discussing patient symptoms, concerns about serious disease, psychosocial issues, and providing reassurance regarding patient worries and concerns). The finding of a statistically significant improvement in QOLRAD emotional distress domain at four months in the comprehensive counselling arm may, therefore, suggest that the discussion of these two 
additional topics may have helped to alleviate the patient's emotional and psychological distress and concerns surrounding their gastrointestinal symptoms.

When implemented in conjunction with medical therapy, the incremental benefits of behavioural modifications and counselling may not be apparent. A study arm in which no template for a counselling intervention would have been provided, as in routine care, was not included because consulted physicians and participating investigators unanimously reported routinely using items of the basic counselling intervention. This physician behaviour may not be generalizable because of probable variability in interest in upper gastrointestinal conditions. Furthermore, patient counselling and education promoted for several medical conditions are difficult to implement in daily practice (27). To our knowledge, the present study is the first to attempt assessing the value of individual counselling in patients with upper gastrointestinal symptoms, specifically heartburn-predominant uninvestigated dyspepsia. In patients with GERD, it has been shown that physicians may overestimate the benefit of treatment and that paying more attention to HRQoL may help physicians better understand patient experiences (28). In patients with mild GERD, a group-based education program showed no effect on HRQoL or use of health care resources at two and 12 months of follow-up (29). In patients with irritable bowel syndrome, a variety of counselling actions have been properly assessed and shown to provide benefit (20,30-32). Variations in the results of studies of therapeutic lifestyle and disease management interventions are expected, given the heterogeneity and complexity of such programs.

Slightly more patients appeared to be completely satisfied with comprehensive counselling than with basic counselling, but the difference was not statistically significant. Although there was no difference in the level of physician satisfaction with the two intervention strategies, a greater proportion of patients in both groups than physicians were more satisfied with the counselling interventions provided. This observation may demonstrate the difficulty encountered by practicing physicians in delivering counselling and education in the usual care setting. Nevertheless, our results show that the majority of subjects in the comprehensive counselling group reported the three components of the intervention as being at least helpful.

\section{REFERENCES}

1. Malagelada JR. The continuing dilemma of dyspepsia. Aliment Phamacol Ther 2001;15(Suppl 1):6-9.

2. Luman W, Ng HS. Survey of dyspepsia management in community. Singapore Med J 2001;42:26-9.

3. Agréus L, Svardsudd K, Talley NJ, et al. Natural history of gastroesophageal reflux disease and functional abdominal disorders: A population-based study. Am J Gastroenterol 2001;96:2905-14.

4. Johanson JF. Critical review of the epidemiology of gastroesophageal reflux disease specific comparisons to asthma and breast cancer. Am J Gastroenterol 2001;96(Suppl 8):S19-21.

5. Eisen G. The epidemiology of gastroesophageal reflux disease: What we know and what we need to know. Am J Gastroenterol 2001;96(Suppl 8):S16-8.

6. Veldhuyzen van Zanten SJO, Bradette M, Chiba N, et al. Evidencebased recommendations for short- and long-term management of uninvestigated dyspepsia in primary care: An update of the Canadian Dyspepsia Working Group (CanDys) clinical management tool. Can J Gastroenterol 2005;19:285-303.

7. Veldhuyzen van Zanten SJO, Flook N, Chiba N, et al. An evidencedbased approach to the management of uninvestigated dyspepsia in the era of Helicobacter pylori. CMAJ 2000;162(Suppl 12):S3-23.
These three components were perceived by patients to be of equal value. The third component ('address the reasons why you consult the physician for these symptoms') was unique to the comprehensive counselling arm and was not considered by patients to be of greater value than the other two; this may be one reason why larger differences in HRQoL and satisfaction were not observed between the two groups.

Although there was a small but statistically significant difference in QOLRAD score measured at four months versus one month between the two groups, there was no difference in symptom control. However, the improvement in HRQoL was maintained during the six-month follow-up despite a progressive decrease in symptom control, whereas the mean and median duration of PPI treatment did not differ significantly between the two groups. This suggests that counselling interventions help to maintain HRQoL beyond the use of drug therapy. Also, no significant differences were shown between the health care costs observed for two counselling groups during the six-month follow-up period of usual care.

There was a statistically significant improvement in baseline QOLRAD score after one month of treatment with esomeprazole for both counselling groups. Similarly, the three types of questionnaires to assess patient symptoms showed significant improvement. These findings are consistent with data in the literature (6,33-42), and support PPIs as the mainstay of initial therapy for patients with heartburn-predominant uninvestigated dyspepsia.

\section{SUMMARY}

Although some of the data show a positive initial trend for comprehensive counselling to improve HRQoL in patients with heartburn-predominant uninvestigated dyspepsia compared with basic counselling, a larger study is required to confirm the value of this approach.

ACKNOWLEDGEMENTS: Pierre Paré had the original idea for the study, designed the protocol and was responsible for drafting the manuscript. Ian Hawes was responsible for data acquisition. Joanna Lee performed the statistical analysis. All authors participated in the analysis and interpretation of the results and the critical revision of the manuscript. The study was supported by funding from AstraZeneca Canada Inc.

8. Talley NJ. American Gastroenterological Association medical position statement: Evaluation of dyspepsia. Gastroenterology 2005;129:1753-5.

9. Talley NJ, Vakil NB, Moayyedi P. American Gastroenterological Association technical review on the evaluation of dyspepsia. Gastroenterology 2005;129:1756-80.

10. Talley NJ, Vakil NB. Guidelines for the management of dyspepsia. Am J Gastroenterol 2005;100:2324-37.

11. Kaltenbach T, Crockett S, Gerson LB. Are lifestyle measures effective in patients with gastroesophageal reflux disease? An evidence-based approach. Arch Int Med 2006;166:965-71.

12. Tougas G, Chen Y, Hwang P, et al. Prevalence and impact of upper gastrointestinal symptoms in the Canadian population: Findings from the DIGEST study. Am J Gastroenterol 1999;94:2845-54.

13. Koloski NA, Talley NJ, Boyce PM. Predictors of health care seeking for irritable bowel syndrome and non-ulcer dyspepsia: A critical review of the literature on symptom and psychosocial factors. Am J Gastroenterol 2001;96:1340-9.

14. Huag TT, Wilhelmsen I, Ursin H, et al. What are the real problems for patients with functional dyspepsia? Scand J Gastroenterol 1995;97-100. 
15. Talley NJ, Zinsmeister AR, Schleck CD, et al. Dyspepsia and dyspepsia subgroups: A population-based study. Gastroenterology 1992;102:1259-68.

16. Lydeard S, Jones R. Factors affecting the decision to consult with dyspepsia: Comparison of consulters and non-consulters. J R Coll Gen Pract 1989;39:495-8.

17. Jansson C, Nordenstedt H, Wallander MA, et al. Severe gastrooesophageal reflux symptoms in relation to anxiety, depression and coping in a population-based study. Aliment Pharmacol Ther 2007;26:683-91.

18. Crawley JA, Hamelin B, Gallagher E. Does it matter why heartburn sufferers seek health care? Gastroenterology 2000;118:A209.

19. Jackson JL, Kroenk K. The effect of unmet expectations among adults presenting with physical symptoms. Ann Intern Med 2001;134:889-97.

20. Monsbakken KW, Vandvik PO, Farup PG, et al. The value of a general therapeutic approach in subjects with irritable bowel syndrome. Aliment Pharmacol Ther 2005;21:21-7.

21. Owens DM, Nelson DK, Talley NJ. The irritable bowel syndrome: Long term prognosis and the physician-patient interaction. Ann Intern Med 1995;122:107-12.

22. Wiklund IK, Junghard O, Grace E, et al. Quality of Life in Reflux and Dyspepsia patients. Psychometric documentation of a new disease-specific questionnaire (QoLRAD). Eur J Surg Suppl 1998;583:41-9.

23. Armstrong DA, Veldhuyzen van Zanten S, Barkun A, et al. Heartburn-dominant, uninvestigated dyspepsia: A comparison of 'PPI-start' and 'H2-RA-start' management strategies in primary care - the CADET-HR Study. Aliment Pharmacol Ther 2005;21:1189-202.

24. Veldhuyzen van Zanten SJO, Tytgat KMAJ, Pollak PT, et al. Can severity of symptoms be used as an outcome measure in trials of non-ulcer dyspepsia and Helicobacter pylori associated gastritis? J Clin Epidemiol 1993;46:273-9.

25. Veldhuyzen van Zanten SJ, Chiba N, Armstrong D, et al. Validation of a 7-point global overall symptom scale to measure the severity of dyspepsia symptoms in clinical trials. Aliment Pharmacol Ther 2006;23:521-9.

26. Shaw MJ, Talley NJ, Beebe TJ, et al. Initial validation of a diagnostic questionnaire for gastroesophageal reflux disease. Am J Gastroenterol 2001;96:52-7.

27. Wilson JF. Patient counselling and education: Should doctors be doing more? Ann Intern Med 2006;144:621-4.

28. Fallone CA, Guyatt GH, Armstrong D, et al. Do physicians correctly assess patient symptom severity in gastro-oesophageal reflux disease? Aliment Pharmacol Ther 2004;20:1161-9.

29. Urnes J, Farup PG, Lydersen S, et al. Patient education in gastrooesophageal reflux disease: A randomized controlled trial. Eur J Gastroenterol Hepatol 2007;19:1104-10.
30. Ilnyckyj A, Balachandra B, Elliott L, et al. Post-traveler's diarrhea irritable bowel syndrome: A prospective study. Am J Gastroenterol 2003;98:596-9.

31. Saito YA, Prather CM, Van Dyke CT, et al. Effects of multidisciplinary education on outcomes in patients with irritable bowel syndrome. Clin Gastroenterol Hepatol 2004;2:576-84.

32. Heitkemper MM, Jarrett ME, Levy RL, et al. Self-management for women with irritable bowel syndrome. Clin Gastroenterol Hepatol 2004:2:585-96.

33. Kulig M, Leodolter A, Vieth M, et al. Quality of life in relation to symptoms in patients with gastro-oesophageal reflux disease - an analysis based on the ProGERD initiative. Aliment Pharmacol Ther 2003;18:767-76.

34. Revicki DA, Sorensen S, Maton PN, et al. Health-related quality of life outcomes of omeprazole versus ranitidine in poorly responsive symptomatic gastroesophageal reflux disease. Dig Dis 1998;16:284-91.

35. Havelund T, Lind T, Wiklund I, et al. Quality of life in patients with heartburn but without esophagitis: Effects of treatment with omeprazole. Am J Gastroenterol 1999;94:1782-9.

36. Johanson JF, Siddique R, Damiano AM, et al. Rabeprazole improves health-related quality of life in patients with erosive gastroesophageal reflux disease. Dig Dis Sci 2002;47:2574-8.

37. Damiano A, Siddique R, Xu X, et al. Reductions in symptom distress reported by patients with moderately severe, nonerosive gastroesophageal reflux disease treated with rabeprazole. Dig Dis Sci 2003;48:657-62.

38. Paré P, Armstrong D, Pericak D, et al. Pantoprazole rapidly improves health-related quality of life in patients with heartburn: A prospective, randomized, double blind comparative study with nizatidine. J Clin Gastroenterol 2003;37:132-8.

39. Revicki DA, Zodet MW, Joshua-Gotlib S, et al. Health-related quality of life improves with treatment-related GERD symptom resolution after adjusting for baseline severity. Health Qual Life Outcomes 2003;1:73.

40. Johnson DA, Orr WC, Crawley JA, et al. Effect of esomeprazole on nighttime heartburn and sleep quality in patients with GERD: A randomized, placebo-controlled trial. Am J Gastroenterol 2005;100:1914-22.

41. de Souza Cury M, Ferrari AP, Ciconelli R, et al. Evaluation of health-related quality of life in gastroesophageal reflux disease patients before and after treatment with pantoprazole. Dis Esophagus 2006;19:289-93.

42. Hansen AN, Bergheim R, Fagertun H, et al. Long-term management of patients with symptoms of gastro-oesophageal reflux disease - a Norwegian randomised prospective study comparing the effects of esomeprazole and ranitidine treatment strategies on health-related quality of life in a general practitioners setting. Int J Clin Pract 2006;60:15-22. 


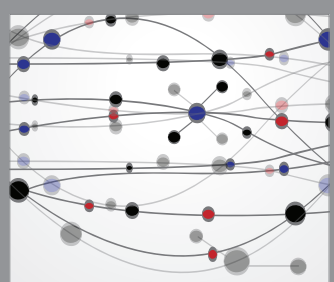

The Scientific World Journal
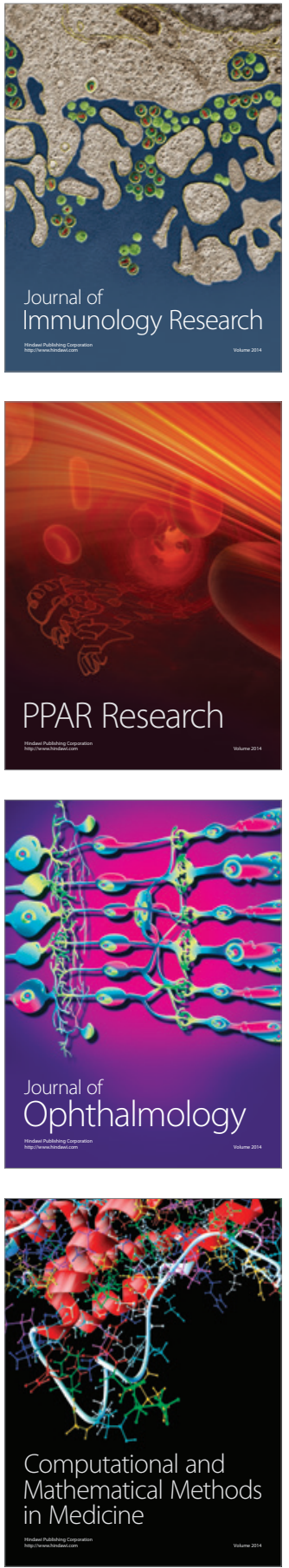

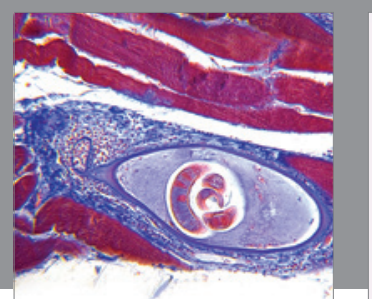

Gastroenterology Research and Practice

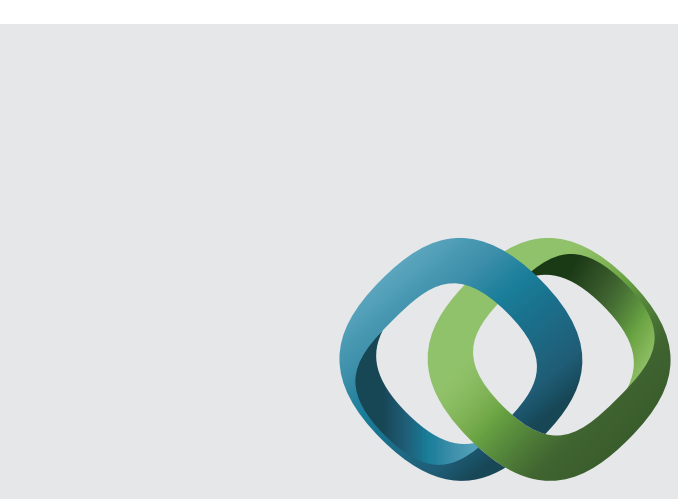

\section{Hindawi}

Submit your manuscripts at

http://www.hindawi.com
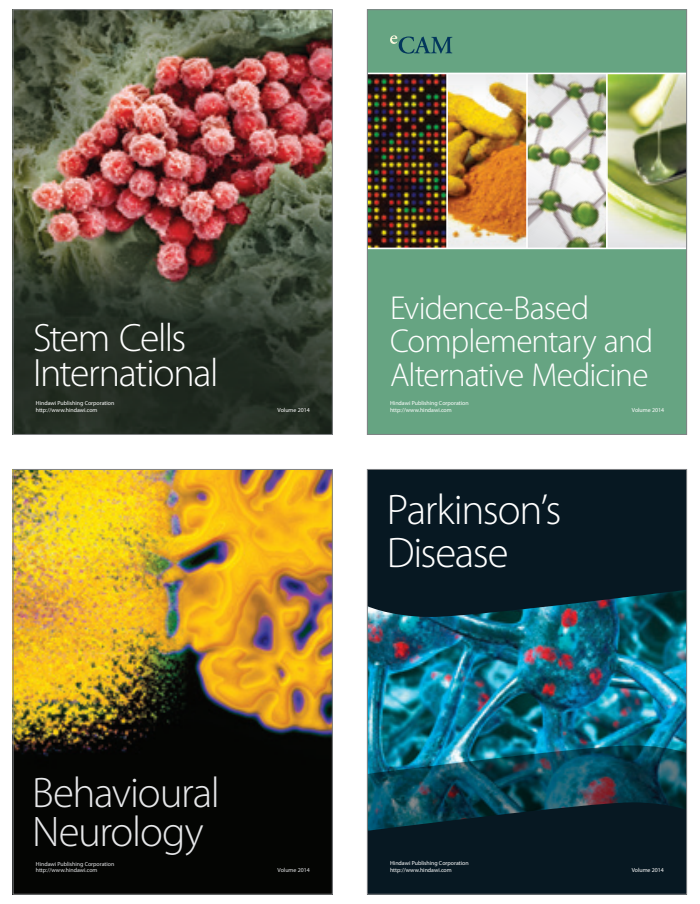
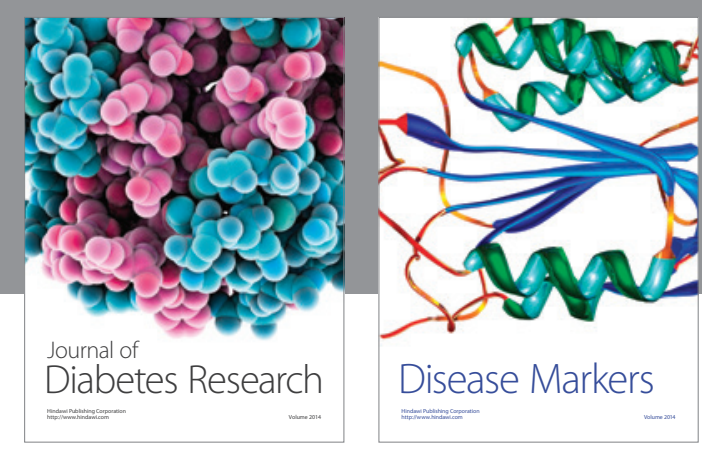

Disease Markers
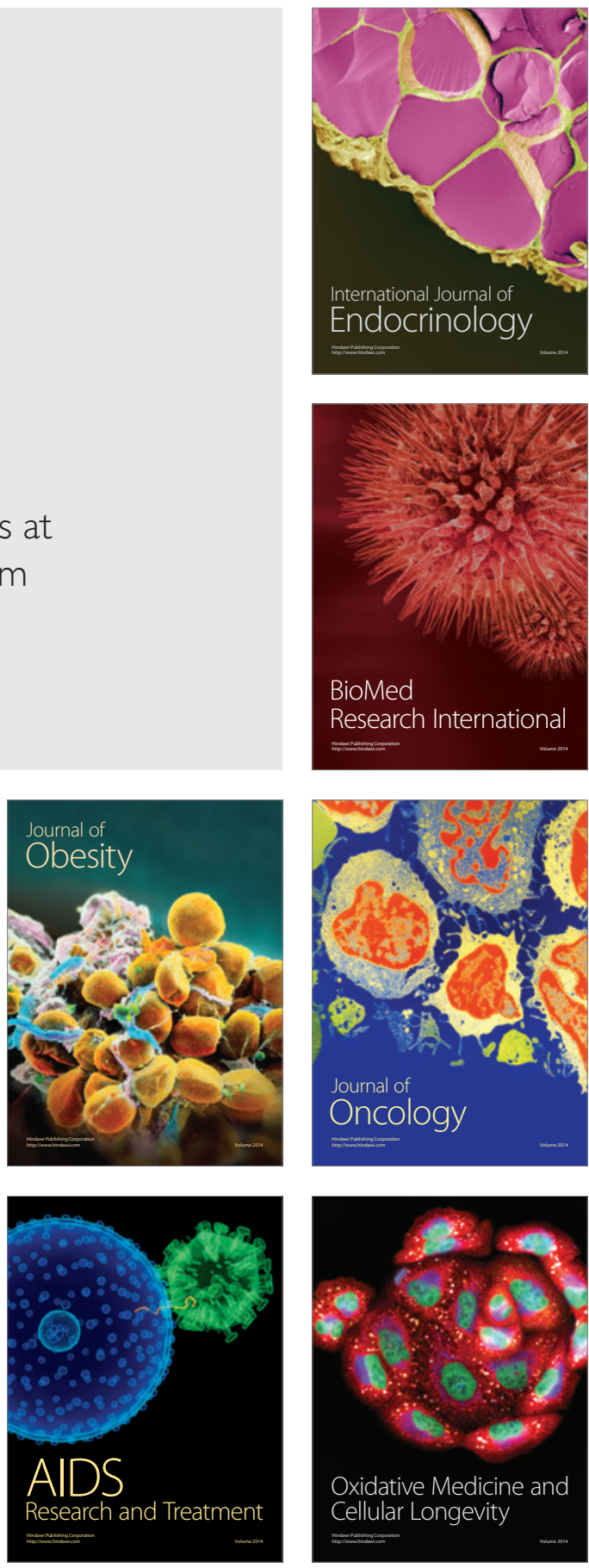